\title{
Effects of initial soil moisture content on soil water and nitrogen transport under muddy water film hole infiltration
}

\author{
Lihua Liu ${ }^{1,2}$, Liangjun Fei ${ }^{1,2^{*}}$, Lin Chen ${ }^{1,2}$, Kun Hao $^{1,2}$, Quanju Zhang ${ }^{1,2}$ \\ (1. State Key Laboratory of Eco-hydraulics in Northwest Arid Region, Xi'an University of Technology, Xi'an 710048, China; \\ 2. Institute of Water Resources and Hydro-electric Engineering, Xi'an University of Technology, Xi'an 710048, China)
}

\begin{abstract}
Film hole irrigation has been widely adopted as an effective water-saving irrigation technology in the arid and semiarid areas of China. To investigate the effects of initial soil moisture content $\left(\theta_{0}\right)$ on soil water and nitrogen transport characteristics under muddy water film hole infiltration, the laboratory experiments were conducted with muddy water film hole infiltration, using five initial soil moisture content treatments. The models for describing the relationships between the cumulative infiltration $(I(t))$ and infiltration duration $(t)$; the relationship among the horizontal and vertical migration distances of the wetting front $\left(F_{x}, F_{z}\right), \theta_{0}$ and $t$, were established. The results showed that the initial soil moisture content had a significant effect on $I(t), F_{x}, F_{z}$ and moisture content distribution in the wetted body. The change of $I(t)$ over $t$ conformed to Kostiakov model. With the increase of $\theta_{0}$, the infiltration coefficient $(K)$ gradually decreased. $\mathrm{NO}_{3}^{-}-\mathrm{N}$ was mainly distributed in the range of the wetting radius of $15 \mathrm{~cm}$, while $\mathrm{NH}_{4}^{+}-\mathrm{N}$ was mainly distributed in the range of the wetting radius of $8 \mathrm{~cm}$. This study can provide a theoretical basis and technical support for film hole irrigation.
\end{abstract}

Keywords: film hole irrigation, muddy water, initial soil moisture content, water and nitrogen transport, water redistribution DOI: $10.25165 /$ j.ijabe.20211404.6024

Citation: Liu L H, Fei L J, Chen L, Hao K, Zhang Q J. Effects of initial soil moisture content on soil water and nitrogen transport under muddy water film hole infiltration. Int J Agric \& Biol Eng, 2021; 14(4): 182-189.

\section{Introduction}

Severe global water shortage and uneven distribution of water resources have attracted wide attention in the 21 st century around the world ${ }^{[1]}$. Water is a type of indispensable basic resource for national economic and social development ${ }^{[2]}$. Owing to the limited rainfall and great soil-moisture evaporation, serious water scarcity has widely emerged in the arid and semiarid areas of northwest China, which is one of the major constraints to agricultural production ${ }^{[3]}$. Therefore, effective utilization of irrigation water under limited precipitation should be considered to increase crop yield while saving water.

Currently, plastic film mulching (PFM) techniques have been widely applied in agricultural practice for grain crops, fruit trees, and vegetable crops ${ }^{[4]}$. Previous research indicated that plastic film mulching can protect seedlings in arid climates, increase the soil temperature, reduce soil water loss by decreasing evaporation from the soil surface ${ }^{[5,6]}$, control weed growth and prevent nutrient losses from leaching, and increase water use efficiency (WUE) as well as improve crop yield ${ }^{[7]}$.

Film hole irrigation (FHI), as effective water-saving irrigation technology, has been developed on the basis of PFM. When

Received date: 2020-07-15 Accepted date: 2021-03-30

Biographies: Lihua Liu, PhD candidate, research interest: theory and new technology of water-saving irrigation, Email: liulihua0712@163.com; Lin Chen, $\mathrm{PhD}$, research interest: theory and new technology of water-saving irrigation, Email: 1036784415@qq.com; Kun Hao, PhD candidate, research interest: theory and new technology of water-saving irrigation, Email: haokgz@126.com; Quanju Zhang, Master candidate, research interest: theory and new technology of water-saving irrigation, Email: 307240987@qq.com.

*Corresponding author: Liangjun Fei, PhD, Professor, research interest: theory and new technology of water-saving irrigation. Xi'an University of Technology, No.5, Jinhua South Road, Xi'an 710048, Shaanxi, China. Tel: +86-13186181693, Email: feiliangjun2008@163.com. irrigating, water flows over the film on the soil surface. There is a thin layer of water depth above the film hole, and water and fertilizers can be adequately infiltrated into the root zone through the film hole ${ }^{[8]}$. Meanwhile, FHI can reduce evaporation and deep percolation, which can increase crop yield and economic efficiency ${ }^{[9,10]}$. FHI has a very promising prospect for widespread application in the irrigation areas of the Yellow River Basin in China $^{[11]}$. Extensive researches on FHI from the aspects of infiltration characteristics and influence factors have been performed by scholars worldwide ${ }^{[11,12]}$, and some empirical models were established. Liu et al. ${ }^{[13]}$ showed that PFM led to the volume moisture content increased by $3.5 \%$ at depths of $0-20 \mathrm{~cm}$ in winter wheat farmland. Compared with conventional surface irrigation, FHI can save $37 \%-45 \%$ water and increase sunflower yield by $23 \%-30 \%{ }^{[14]}$. Several fields and laboratory experiments have been carried out to study the effects of influence factors (e.g., soil texture, soil bulk density, film hole diameter, sediment content.) on infiltration characteristics under $\mathrm{FHI}^{[15-17]}$. Dong et al. ${ }^{[18]}$ found that the relationship between the horizontal/vertical wetting front migration distances and infiltration duration was a significant power function. Jin et al. ${ }^{[19]}$ established a free infiltration model of muddy water film hole irrigation with different initial moisture contents through indoor experiments. Zhong et al. ${ }^{[20]}$ concluded that in the free infiltration under muddy water irrigation, the cumulative infiltration volume per unit area of film hole, the stable infiltration rate, and the horizontal wetting front migration distance decreased with the increase of the soil bulk density. Jie et al. ${ }^{[17]}$ established a quantitative model of FHI infiltration process performed indoors with soil boxes, and the simulation model could generally accurately simulate the movement of the wetting front and the changes in the soil moisture volume under FHI.

Most of the irrigation areas are muddy water irrigation areas in the Yellow River Basin of China, and muddy water irrigation primarily occurs in the Yellow River Basin of China ${ }^{[21]}$. Some 
progress has been made in the study of infiltration characteristics of film hole irrigation, but few studies have been conducted on characteristics of water and nitrogen transport under different soil moisture content of muddy water film hole infiltration. Hence, there is a gap in understanding how the muddy water film hole irrigation in combination with different soil moisture content affects soil water and nitrogen transport. The research on soil nitrogen transport and transformation and water fertilizer coupling effect under muddy water film hole irrigation highlights the characteristics and advantages of muddy water FHI in China. Therefore, the objective of this study is to investigate the effects of the initial soil moisture content on soil water and nitrogen transport characteristics under muddy water film hole infiltration and to develop an empirical model for predicting the cumulative infiltration of film hole irrigation. It is anticipated that the findings from this study will provide the theoretical foundation and practical guidelines for applications of film hole irrigation.

\section{Materials and methods}

\subsection{Experimental materials}

The experiments were conducted from July to August 2019 at the State Key Laboratory of Eco-hydraulics in Northwest Arid Region, Xi'an, China. The experimental soil samples were taken from Hongqing, Xi'an, in September 2018. The soil samples were collected from the depths of $0-30 \mathrm{~cm}$, air dried and then sieved through a 2-mm sieve. The initial soil moisture content was measured using the oven-drying method. Soil particle composition was determined by using a Mastersizer-2000 laser particle size analyzer. According to the international soil texture classification standards, the soil type used in this experiment was silt loam (30.63\% sand, $56.59 \%$ silt, and $9.78 \%$ clay). The saturated moisture content of the soil sample was about $38 \%$.

According to the soil moisture content in the actual irrigation process, five initial moisture contents $\left(\theta_{0}=6.02 \%, 7.40 \%, 8.23 \%\right.$, $10.08 \%$, and $13.20 \%$, mass moisture content, the same below) were employed in the laboratory experiments. The diameter of the film hole was $6 \mathrm{~cm}$, the soil bulk density was $1.30 \mathrm{~g} / \mathrm{cm}^{3}$, and the fertilizer solution (Calcium Ammonium Nitrate, $\left.5 \mathrm{Ca}\left(\mathrm{NO}_{3}\right)_{2} \cdot \mathrm{NH}_{4} \mathrm{NO}_{3} \cdot 10 \mathrm{H}_{2} \mathrm{O}\right)$ concentration was $600 \mathrm{mg} / \mathrm{L}$. The background values of $\mathrm{NO}_{3}^{-}-\mathrm{N}$ and $\mathrm{NH}_{4}^{+} \mathrm{N}$, in the soil sample were $6.25 \mathrm{mg} / \mathrm{kg}$ and $15 \mathrm{mg} / \mathrm{kg}$, respectively. The sediment concentration of the muddy water was set at $2 \%$.

\subsection{Experimental design and method}

Figure 1 illustrates the schematic diagram of the experimental set-up. Considering the symmetry characteristics of film hole infiltration, the soil container, composed of 20-mm thick transparent plexiglass, was designed with the internal dimensions of length $30 \mathrm{~cm}$, width $30 \mathrm{~cm}$ and height $40 \mathrm{~cm}$. The bottom of the soil container had numerous $2 \mathrm{~mm}$ parallel air vents for ventilation, and both sides of the soil container were side holes from which the soil sample could be taken; the diameter of each hole and the distance between the holes were $1 \mathrm{~cm}$ and $3 \mathrm{~cm}$, respectively. A Mariotte bottle was fixed with the height adjustable and provided a constant infiltration head for the film hole device through a rubber hose; this bottle had an inner diameter of $9 \mathrm{~cm}$ and a height of $100 \mathrm{~cm}$. In order to reduce the deposition of sediment as much as possible, the Mariotte bottle was provided with an automatic agitating system. Blades in the agitating system were driven by an electromotor to revolve, thereby agitating the muddy water. It was calculated that the volume of the blades was only $2 \%$ of the volume of the Mariotte bottle; the volume of the blades was thus neglected.

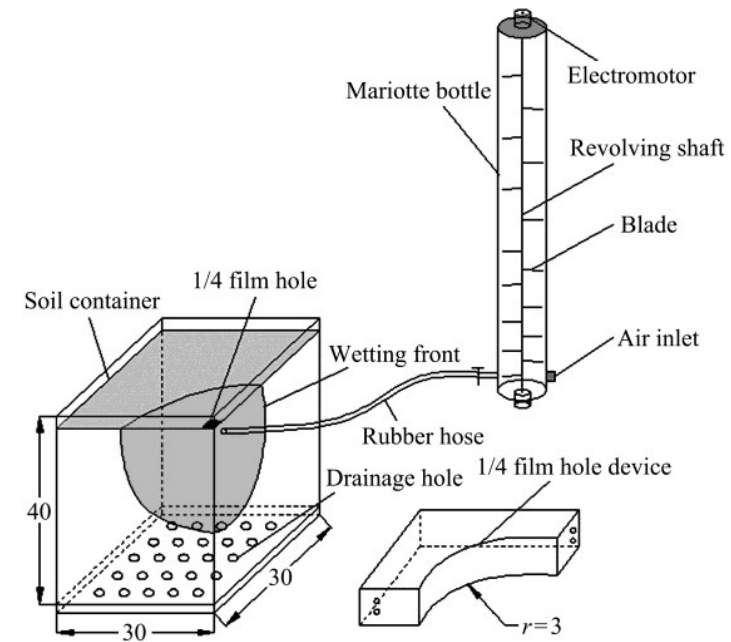

Note: The length, width and height of the soil container are in $\mathrm{cm}$; the radius $r$ of $1 / 4$ film hole device is in $\mathrm{cm}$.

Figure 1 Schematic diagram of experimental set-up

The initial soil moisture content $\left(\theta_{0}\right)$ was measured by the oven drying method before the experiment. Before the soil box was filled with soil, transparent adhesive tape was placed on both sides of the soil box to prevent the soil from falling out of the box. The soil was then rammed, based on $\theta_{0}$ and the predetermined bulk density $\left(1.30 \mathrm{~g} / \mathrm{cm}^{3}\right)$, and by layers $(5 \mathrm{~cm}$ thick per layer), into the soil container, during which the surface of each soil layer was roughened. Plastic film was used to cover the soil surface and a $1 / 4$ film hole device made of $5 \mathrm{~mm}$ thick plexiglass was fixed at one corner of the soil container. The film hole had a radius of $3.0 \mathrm{~cm}$ and the film hole device had a water head height of $2.0 \mathrm{~cm}$.

During the experiment, the infiltration duration and the water level in the Mariotte bottle were recorded at progressively prolonged time intervals, and the changes of the wetted body were observed. After the infiltration was over, a soil drill was used to collect soil samples at intervals of $2.5 \mathrm{~cm}$ in the horizontal and vertical direction of the film hole center, respectively. Each time the soil of a thickness of $5 \mathrm{~cm}$ was collected. Each soil sample was divided into 2 parts, one part was used to measure moisture content, and the other part was used to measure soil $\mathrm{NO}_{3}^{-}-\mathrm{N}$ and $\mathrm{NH}_{4}^{+}-\mathrm{N}$ content by a HACH DR/4000 spectrophotometer.

\subsection{Data analysis and processing}

The statistical analysis software Microsoft Excel 2016 (Microsoft, USA) was used for data processing and analysis. The water content distribution of soil profile was drawn by SURFER 9.0 software program.

Using Excel software, the cumulative infiltration volume per unit film hole area was fitted by the Kostiakov infiltration model ${ }^{[22]}$, which follows:

$$
I(t)=K t^{\alpha}
$$

where, $I(t)$ is the cumulative infiltration volume per unit film hole area, $\mathrm{cm} ; t$ is the infiltration duration, $\min ; K$ is an infiltration coefficient, $\mathrm{cm} / \mathrm{min}^{\alpha} ; \alpha$ is the infiltration index.

\section{Results}

\subsection{Infiltration capacity}

\subsubsection{Cumulative infiltration per unit film hole area}

The cumulative infiltration per unit film hole area $(I(t))$ is shown in Figure 2. $I(t)$ differed greatly under different initial soil moisture content $\left(\theta_{0}\right)$, indicating that $\theta_{0}$ had a significant effect on $I(t)$. 


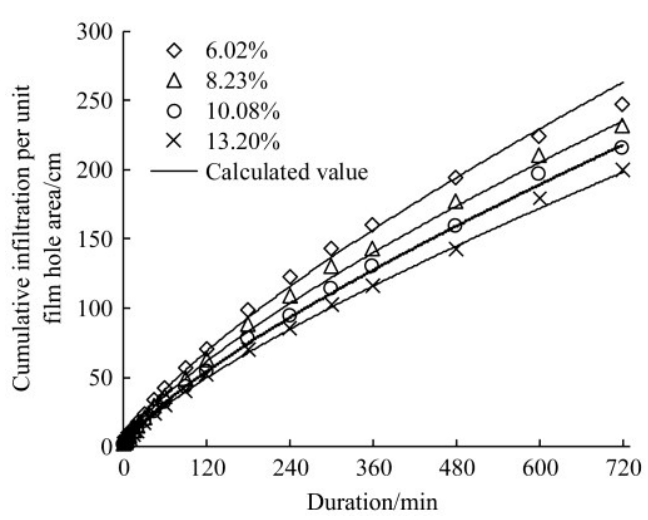

Figure 2 Curves of cumulative infiltration per unit film hole area under different initial soil moisture contents

The cumulative infiltration volume per unit film hole area $I(t)$ and the infiltration duration $(t)$ was fitted by Equation (1), and the result is shown in Table 1. The correlation coefficients $(R)$ for all treatments were all larger than the critical correlation coefficient $\left(R_{0.01}=0.6614\right)$, indicating that the Kostiakov infiltration model could describe the relationship between cumulative infiltration per unit film hole area and infiltration duration.

According to Table $1, K$ gradually decreased and $\alpha$ gradually increased as the initial moisture content increased. Specifically, the initial moisture content increased from $6.02 \%$ to $13.20 \%$; $K$ decreased from 1.9270 to 1.2324 , and $\alpha$ increased from 0.7472 to 0.7721 . $K$ reflects the slope degree of the cumulative infiltration curve. The larger the $K$ is, the greater the slope degree of the curve is, i.e., the greater infiltration amount. The $\alpha$ reflects the bending degree of the cumulative infiltration curve, the larger the $\alpha$ is, the smaller the bending degree of the curve is. It was found that $K, \alpha$ and $\theta_{0}$ conformed to a linear function relationship, as following:

$$
\begin{gathered}
K=-10.1380 \theta_{0}+2.5103, R^{2}=0.9253 \\
\alpha=0.4030 \theta_{0}+0.7218, R^{2}=0.7522
\end{gathered}
$$

The coefficients of determination $\left(R^{2}\right)$ of the fitting relationship of Equations (2) and (3) were larger than 0.75. The Equations (2) and (3) were put into Equation (1), giving a model of the relationship among $I(t), t$, and $\theta_{0}$, as following:

$$
I\left(\theta_{0}, t\right)=\left(-10.1380 \theta_{0}+2.5103\right) t^{0.4030 \theta_{0}+0.7218}, 0 \leq t \leq 720
$$

Equation (4) was used to calculate the cumulative infiltration per unit film hole area $\left(\theta_{0}=7.40 \%\right)$. Table 2 shows the comparison between calculated and experimental measured values of the cumulative infiltration per unit film hole area, and its relative error values are less than $\pm 7.98 \%$, indicating that Equation (4) could be used to calculate the cumulative infiltration per unit film hole area of muddy water film hole infiltration in different initial moisture contents.

Table 1 Fitted infiltration parameter values

\begin{tabular}{cccc}
\hline$\theta_{0} / \%$ & $K / \mathrm{cm} \cdot \min ^{-\alpha}$ & $\alpha$ & $R^{2}$ \\
\hline 6.02 & 1.9270 & 0.7472 & 0.9946 \\
8.23 & 1.7184 & 0.7476 & 0.9924 \\
10.08 & 1.3588 & 0.7716 & 0.9971 \\
13.20 & 1.2324 & 0.7721 & 0.9949 \\
\hline
\end{tabular}

Table 2 Comparison between calculated and measured cumulative infiltrations $\left(\theta_{0}=\mathbf{7 . 4 0 \%}\right)$

\begin{tabular}{lccccccccccc}
\hline Duration/min & 30 & 60 & 120 & 180 & 240 & 300 & 360 & 480 \\
\hline Measured value/cm & 22.52 & 38.96 & 66.28 & 94.76 & 114.08 & 139.16 & 155.88 & 190.12 & 223.20 & 244.00 \\
Calculated value/cm & 22.69 & 38.20 & 64.31 & 87.23 & 108.28 & 128.05 & 146.86 & 182.31 & 215.60 & 247.27 \\
Relative error/\% & 0.74 & -1.96 & -2.97 & -7.95 & -5.08 & -7.98 & -5.79 & -4.11 & -3.40 & 1.34 \\
\hline
\end{tabular}

\subsubsection{Characteristics of wetting front migration}

The variations of the horizontal and vertical wetting fronts are shown in Figure $3 \mathrm{a}$ and Figure $3 \mathrm{~b}$, respectively. It can be observed from Figure $3 \mathrm{a}$ and Figure $3 \mathrm{~b}$ that the wetting front continues to advance as the length of time increases, the horizontal and vertical wetting front migration distance increased gradually with the increase of $\theta_{0}$. When the water supply was started, the film hole device was immediately filled with water. Therefore, at the initial stage of infiltration, the horizontal wetting front migration distance rapidly increased to the radius of the film hole, which was significantly larger than the vertical wetting front migration distance. Because the water infiltrating in the vertical direction was affected by the matrix potential as well as the gravity potential, with the passage of time during the free infiltration of different initial moisture content under the muddy water film hole infiltration, the vertical wetting front migration distance gradually approached the horizontal wetting front migration distance and even exceeded the horizontal migration distance at a time when the infiltration proceeded for about $180 \mathrm{~min}$.

Based on the analysis, it was found that there was a very significant power function relationship between the horizontal and vertical wetting front migration distance and $t$, as following:

$$
\begin{gathered}
F_{x}=A t^{B}+r \\
F_{z}=C t^{D}
\end{gathered}
$$

where, $F_{x}$ and $F_{z}$ are horizontal and vertical migration distance of the wetting front, respectively, $\mathrm{cm} ; A$ and $B$ are coefficients of migration, $\mathrm{cm} / \mathrm{min}^{\alpha} ; C$ and $D$ are fitting parameters; $r$ is the film hole radius, $r=3 \mathrm{~cm}$.

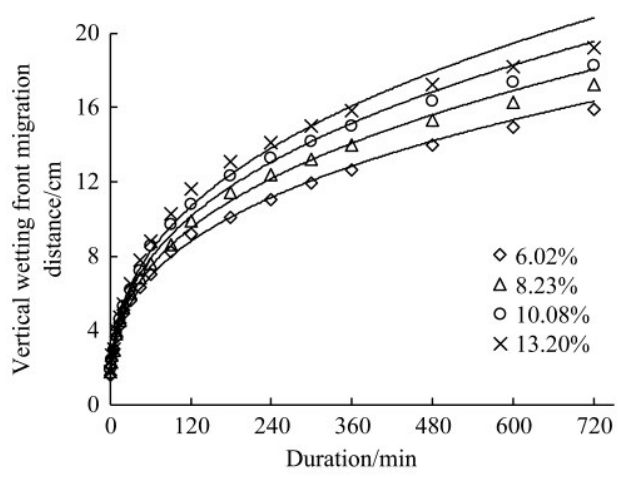

a. Vertical wetting front migration distance

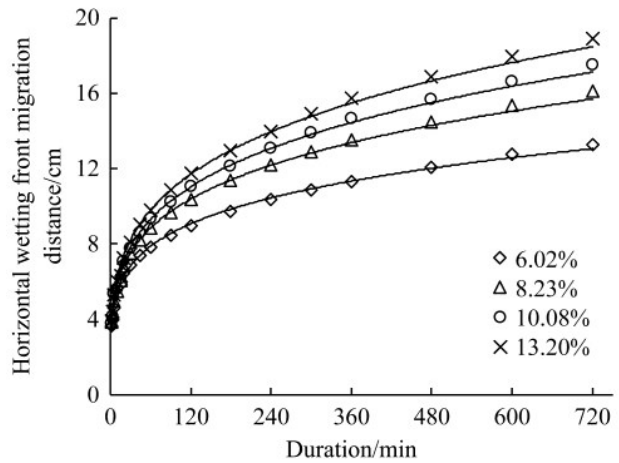

b. Horizontal wetting front migration distance

Figure 3 Curves of the wetting front migration distance 
The data from Figure $3 \mathrm{a}$ and Figure $3 \mathrm{~b}$ were fitted with Equations (5) and (6), and listed in Table 3. The coefficients of determination $\left(R^{2}\right)$ were all larger than 0.96 , indicating that the power function could adequately describe the relationship between $F_{x}, F_{z}$ and $t$.

Table 3 Fitting parameters of relationship between wetting front migration distance and infiltration time

\begin{tabular}{cccccccc}
\hline & \multicolumn{3}{c}{$F_{x}=A t^{B}+3$} & & \multicolumn{3}{c}{$F_{z}=C t^{D}$} \\
\cline { 2 - 5 } \cline { 5 - 7 } & $A$ & $B$ & $R^{2}$ & $C$ & $D$ & $R^{2}$ \\
\hline 6.02 & 0.8547 & 0.3986 & 0.9642 & 1.6743 & 0.3461 & 0.9985 \\
8.23 & 0.9848 & 0.4097 & 0.9865 & 1.7077 & 0.3583 & 0.9968 \\
10.08 & 0.9773 & 0.4287 & 0.9780 & 1.7500 & 0.3666 & 0.9942 \\
13.20 & 1.0550 & 0.4296 & 0.9866 & 1.7842 & 0.3734 & 0.9847 \\
\hline
\end{tabular}

The fitting parameters $A, C$ and $B, D$ were regarded as the coefficient and index of the wetting front migration, respectively. It could be found that $A, C$ and $B, D$ increased significantly with the increase of $\theta_{0}$ (Figure 4).

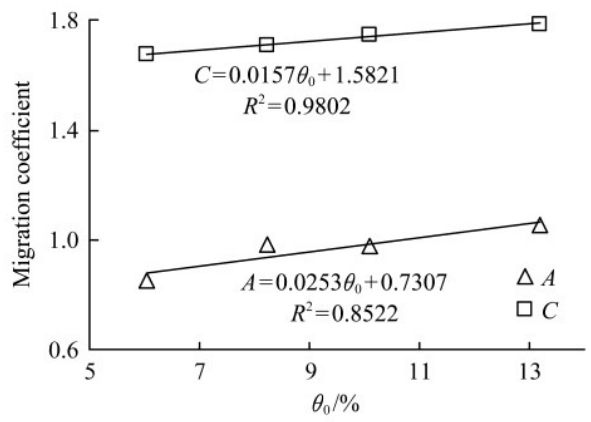

a. Migration coefficient

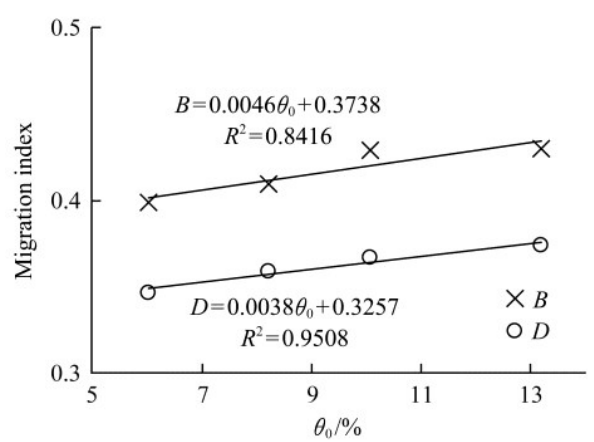

b. Migration index

Figure 4 Relationship between the wetting front parameters and initial moisture content

According to Figure 4, the coefficients of determination $\left(R^{2}\right)$ in equations about $A, B, C$ and $D$ were larger than 0.8416 , indicating that the coefficients $A, C$ and indices $B, D$ of the wetting front migration and $\theta_{0}$ were significant. By substituting expressions $A$, $B, C$ and $D$ into Equations (5) and (6), respectively, empirical models about the $F_{x}, F_{z}$ and $\theta_{0}$ could be obtained, as follows:

$$
\begin{gathered}
F_{x}=\left(0.0253 \theta_{0}+0.7037\right) t^{0.0046 \theta_{0}+0.3738}+r \\
F_{z}=\left(0.0157 \theta_{0}+1.5821\right) t^{0.0038 \theta_{0}+0.3257}
\end{gathered}
$$

In order to verify the reliability of the above empirical models, the horizontal and vertical wetting front migration distances $\left(\theta_{0}=\right.$ $7.40 \%$ ) were calculated by using Equations (7) and (8), respectively. The calculated values were compared with measured values (Figure 5). It could be observed from Figure 5 that the relative errors between the values of the horizontal and vertical migration distances of the wetting front calculated by Equations (7) and (8) and the practically measured values were relatively small, indicating that the empirical models (7) and (8) could predict the vertical and horizontal migration distances.

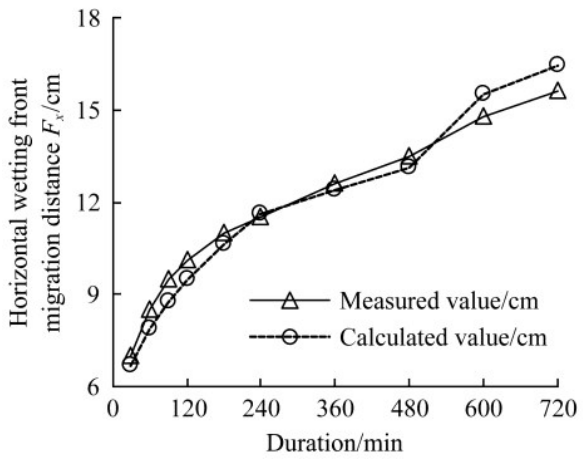

a. Horizontal wetting front migration distance

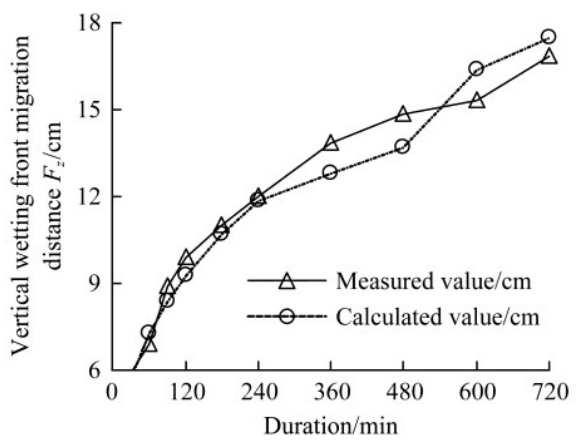

b. Vertical wetting front migration distance

Figure 5 Comparison of calculated and measured values of horizontal and vertical wetting front migration distances

$$
\left(\theta_{0}=7.40 \%\right)
$$

\subsection{Moisture content distribution in the wetted body}

Due to the axisymmetric nature of the wetted body in the vertical axis direction, soil samples were taken from one side of the soil container to obtain the soil moisture content. The water content distribution was drawn using SURFER 11.0 based on a gridding method called "Kriging" available in the software by taking the film hole center as the starting point (Figure 6). It could be observed from Figure 6 that there was a difference in moisture content distribution of muddy water film hole infiltration in different initial moisture contents, and the moisture content distribution isoline was in the shape of a semi ellipse. The higher the initial soil water content was, the larger the migration rate of the wetting front and the volume of the corresponding wetted body were. At the same time, the higher the initial moisture content was, the higher the moisture content was at the same location in the wetted body.

In order to analyze moisture content distribution in the wetted body, in a more detailed way, the measured data of soil moisture content of redistribution $24 \mathrm{~h}$ and $48 \mathrm{~h}$ in the vertical direction of the film hole center were analyzed, as shown in Figure $7 \mathrm{a}$ and Figure $7 \mathrm{~b}$, respectively. Taking the water content in the wetted body at a vertical depth of $15 \mathrm{~cm}$ at the film hole center as an example, when $\theta_{0}$ was $6.02 \%, 7.40 \%, 8.23 \%, 10.08 \%$ and $13.20 \%$, the corresponding water content was $10.44 \%, 13.00 \%, 14.38 \%$, $15.54 \%, 20.59 \%$, respectively. If $\theta_{0}=6.02 \%$ was taken as a benchmark, the increase of water content will be $24.52 \%, 13.22 \%$, $11.11 \%$, and $48.37 \%$, respectively. This showed that a relatively high initial soil moisture content within a certain range was more conducive to the infiltration of water into the soil. According to Figure $7 \mathrm{~b}$, the soil moisture content decreased in the wetted body upper layer, and soil moisture content gradually increased in the 
wetted body lower layer. As the redistribution progresses, the soil moisture content tended to be even distributed in the wetted body. Specifically, the moisture content in the soil within the depth of $0-15 \mathrm{~cm}$ decreased significantly and exhibited a tendency of gradually becoming uniformly distributed, which was especially obvious with the soil in the vicinity of the film hole; while the moisture content in the soil within the depth of $15-30 \mathrm{~cm}$ showed an increasing trend. The maximum wetted depths of the wetted body were $16 \mathrm{~cm}, 22 \mathrm{~cm}$, and $27 \mathrm{~cm}$ at the time when the infiltration was over and during the redistribution $24 \mathrm{~h}$ and $48 \mathrm{~h}$. At a depth of $10 \mathrm{~cm}$ in the vertical direction of the film hole center, the moisture content at the end of the infiltration and during the redistribution 24 and $48 \mathrm{~h}$ were $25.47 \%, 21.46 \%$, and $17.70 \%$, respectively. If the moisture content in the soil at the end of the infiltration was taken as a benchmark, then the decreases of the moisture content in the soil during the redistribution 24 and $48 \mathrm{~h}$ were $15.74 \%$ and $30.51 \%$. The moisture content at a depth of $20 \mathrm{~cm}$ at the end of the infiltration and redistribution 24 and $48 \mathrm{~h}$ were $6.02 \%, 8.61 \%$, and $12.05 \%$, respectively. If the moisture content in the soil at the end of the infiltration was taken as a benchmark, then the increases of the moisture content in the soil during the redistribution 24 and $48 \mathrm{~h}$ were $43.02 \%$ and $100.17 \%$. This was mainly because, in the process of redistribution of water in the soil, the water in the wetted body was redistributed under the action of gravity potential and matrix potential, and the soil outside the wetted body was in a state of absorbing water. Under the action of the water potential gradient, the water continued to move downward and formed a new wetted body. At the end of infiltration, the soil moisture content was higher within the depth of $0-15 \mathrm{~cm}$, and during the redistribution process, it moved to the surrounding areas with lower water content, and underwent a dehydration process. The water of soil depth $15-30 \mathrm{~cm}$ was supplied thereto by the upper layer of soil, and in the meantime, it also absorbed water through the soil matrix suction. The moisture content in the soil, therefore, tended to be uniform throughout the wetted body after redistribution $48 \mathrm{~h}$.

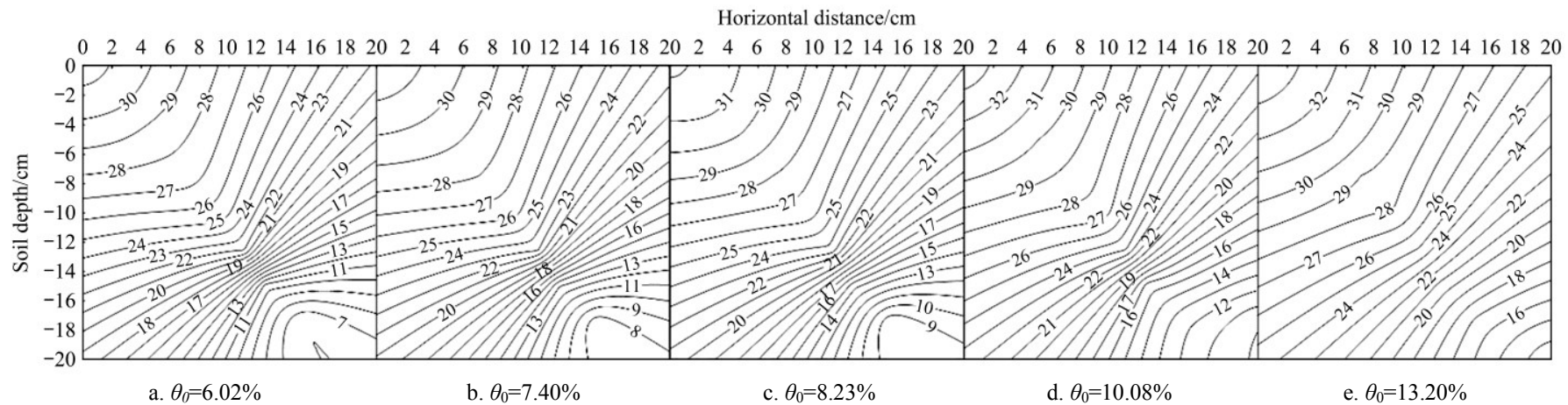

Figure 6 Moisture content distribution in the wetted body at the end of experiments

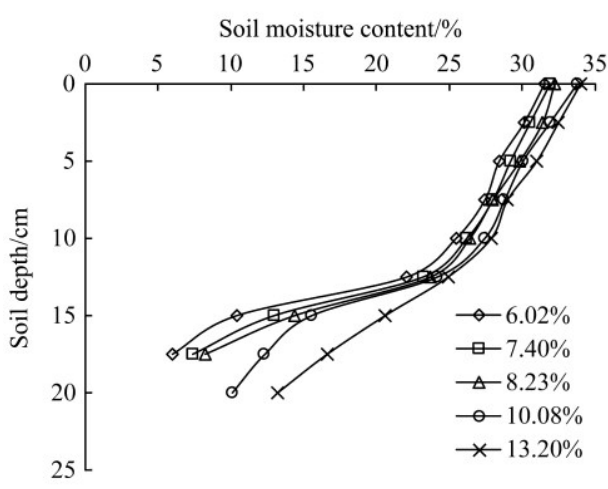

a. Soil moisture content at the end of the infiltration

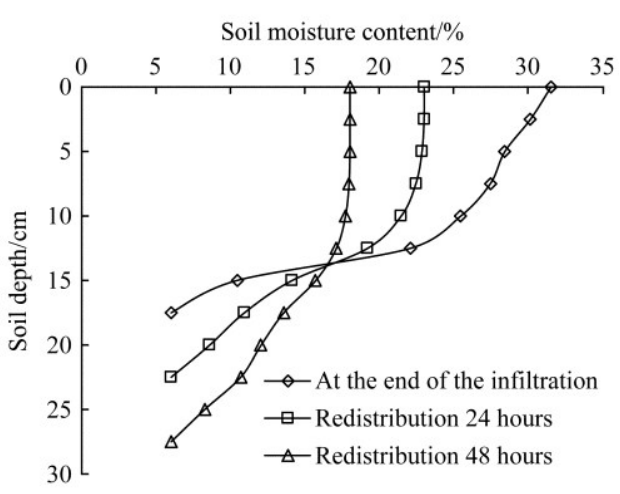

b. Soil moisture content after redistribution $\left(\theta_{0}=6.02 \%\right)$

Figure 7 Soil moisture content in the vertical direction of the film hole center

\subsection{Transport characteristics of nitrogen in the wetted body}

\subsubsection{Transport characteristics of $\mathrm{NO}_{3}^{-}-\mathrm{N}$}

Figure 8 shows the measured values of $\mathrm{NO}_{3}^{-} \mathrm{N}$ content in the wetted body. It could be observed from Figure $8 \mathrm{a}$ and Figure $8 \mathrm{~b}$ that the $\mathrm{NO}_{3}^{-}-\mathrm{N}$ content increased both in the vertical and horizontal direction with the increase of initial moisture content. At the center of the film hole, the $\mathrm{NO}_{3}^{-}-\mathrm{N}$ content was 44.30, 45.50, 46.01, $46.26,48.44 \mathrm{mg} / \mathrm{kg}$, respectively; if $\theta_{0}=6.02 \%$ was taken as a benchmark, then the increases of $\mathrm{NO}_{3}^{-}-\mathrm{N}$ content in the wetted body were $2.69 \%, 1.16 \%, 0.56 \%$, and $4.93 \%$, respectively. According to the previous analysis, the higher the initial moisture content was, the greater the cumulative infiltration volume was, the larger the volume of the wetted body was, and the greater the distribution area of $\mathrm{NO}_{3}^{-}-\mathrm{N}$ was in the soil of the wetted body. Within $720 \mathrm{~min}$ of infiltration duration, the $\mathrm{NO}_{3}^{-}-\mathrm{N}$ was distributed mainly within
$15 \mathrm{~cm}$ from the film hole under different soil initial moisture content, which further embodied the advantages of the film hole irrigation. In other words, the fertilizer can be retained in the shallow soil of concentrated distribution in the root area of crops under film hole irrigation, which is not only beneficial to the absorption and utilization of nutrients by crops but also can improve the utilization rate of nitrogen fertilizer. At the same time, it is not easy to have deep percolation in the process of film hole irrigation, and it can save water and reduce the pollution of $\mathrm{NO}_{3}^{-}-\mathrm{N}$ to groundwater.

It can be seen from Figures $8 \mathrm{c}$ and $8 \mathrm{~d}$ that the $\mathrm{NO}_{3}^{-}-\mathrm{N}$ contents in the wetted body varied significantly with the proceeding of the redistribution. In general, with the redistribution of water in the soil, $\mathrm{NO}_{3}^{-}-\mathrm{N}$ continued to migrate downward. Because $\mathrm{NO}_{3}^{-}-\mathrm{N}$ and soil colloids have the same charges, which are all negative, $\mathrm{NO}_{3}^{-}-\mathrm{N}$ 
cannot be easily absorbed by soil colloids, but easily migrate with the diffusion of water. In the process of water infiltration into the soil, the water content in the wetted body decreased gradually with the increase of the distance away from the center of the film hole, and decreased sharply at the wetting front to an extent close to the initial moisture content of the soil. Therefore, the $\mathrm{NO}_{3}^{-}-\mathrm{N}$ content in the soil within this range decreases rapidly and almost approaches its background value. In addition, the $\mathrm{NO}_{3}^{-}-\mathrm{N}$ content decreased gradually in the upper soil layers, while the lower soil layers formed a new wetted body because of the water redistribution, and the $\mathrm{NO}_{3}^{-}-\mathrm{N}$ content thereby increased. Specifically, within redistribution $24 \mathrm{~h}$, within the depth of $0-5 \mathrm{~cm}$, the $\mathrm{NO}_{3}^{-}-\mathrm{N}$ contents in the wetted body were almost the same as that at the end of the infiltration. From the water redistribution curves in Figure 7b, it could be seen that the water content in soil decreased significantly within the depth of $0-5 \mathrm{~cm}$ and the distribution tended to become gradually even after redistribution

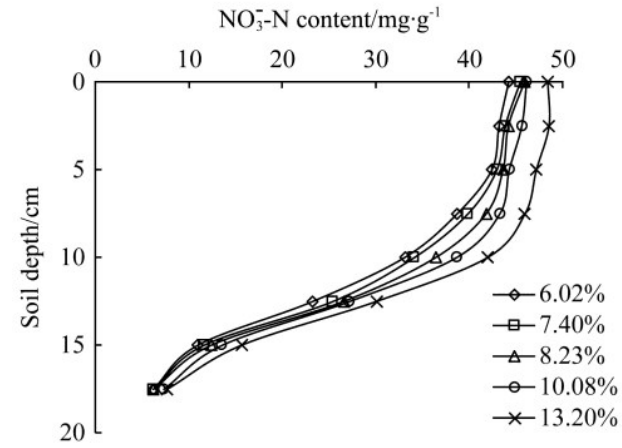

a. $\mathrm{NO}_{3}^{-}-\mathrm{N}$ content in the vertical direction at the end of the infiltration

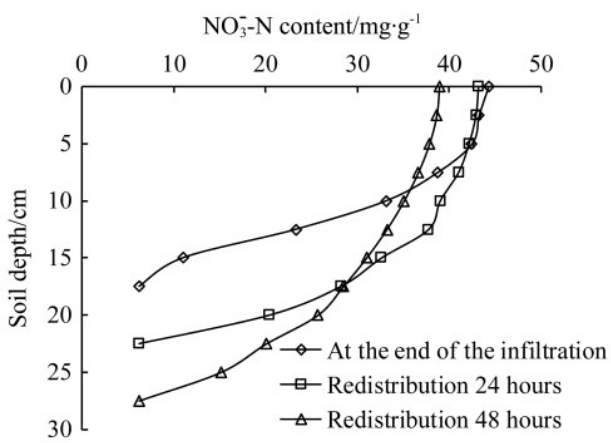

c. $\mathrm{NO}_{3}^{-}-\mathrm{N}$ content in the vertical direction after redistribution $\left(\theta_{0}=6.02 \%\right)$
$24 \mathrm{~h}$, which indicates that the transport and distribution of $\mathrm{NO}_{3}^{-} \mathrm{N}$ in the wetted body during redistribution $24 \mathrm{~h}$ was different from that of water during the infiltration stage. In the infiltration stage, the migration of $\mathrm{NO}_{3}^{-}-\mathrm{N}$ was mainly due to the convection effect, but in the process of redistribution, the convection effect was relatively small and therefore the transport of $\mathrm{NO}_{3}^{-}-\mathrm{N}$ with the movement of water was not obvious. The $\mathrm{NO}_{3}^{-}-\mathrm{N}$ content increased within the depth of $5-30 \mathrm{~cm}$, which was especially obvious in the region of the wetting front. In the soil near the wetting front, the large concentration gradient of $\mathrm{NO}_{3}^{-}-\mathrm{N}$, weak convection, and strong molecular diffusion resulted in the $\mathrm{NO}_{3}^{-} \mathrm{N}$ content increasing significantly. Within redistribution $48 \mathrm{~h}$, the $\mathrm{NO}_{3}^{-}-\mathrm{N}$ content within the depth of $0-10 \mathrm{~cm}$ decreased significantly compared with the end of infiltration, and the distribution tended to gradually become uniform. In addition, the $\mathrm{NO}_{3}^{-}-\mathrm{N}$ content within the depth of 10-30 cm increased, which was consistent with the change of the content of $\mathrm{NO}_{3}^{-}-\mathrm{N}$ within redistribution $24 \mathrm{~h}$.

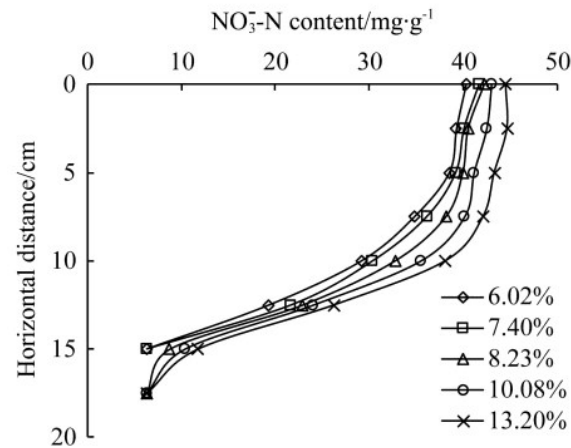

b. $\mathrm{NO}_{3}^{-}-\mathrm{N}$ content in the horizontal direction at the end of the infiltration

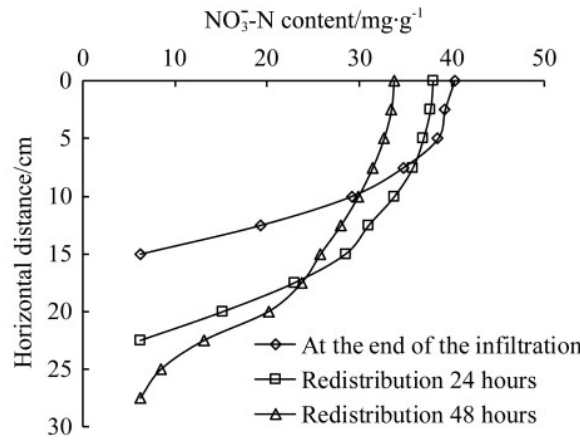

d. $\mathrm{NO}_{3}^{-}-\mathrm{N}$ content in the horizontal direction after redistribution $\left(\theta_{0}=6.02 \%\right)$

Figure 8 Soil $\mathrm{NO}_{3}^{-}-\mathrm{N}$ content in the horizontal and vertical direction of the film hole center

\subsubsection{Transport characteristics of $\mathrm{NH}_{4}^{+}-\mathrm{N}$}

Figure 9 shows the measured values of $\mathrm{NH}_{4}^{+} \mathrm{N}$ content in the wetted body. It could be observed from Figures $9 \mathrm{a}$ and $9 \mathrm{~b}$ that the $\mathrm{NH}_{4}^{+} \mathrm{-}$ contents in the wetted body were the highest at the film hole center. $\mathrm{NH}_{4}^{+}-\mathrm{N}$ was mainly distributed in the range of $8 \mathrm{~cm}$ from the film hole center. In the part of the wetted body that was outside of the $8 \mathrm{~cm}$ range, the $\mathrm{NH}_{4}^{+} \mathrm{N}$ content was significantly reduced. Within the depth of $15-20 \mathrm{~cm}$ from the film hole center, although the wetting front arrived, the $\mathrm{NH}_{4}^{+} \mathrm{-}$ content was not different from the background value of $\mathrm{NH}_{4}^{+} \mathrm{N}$ in the wetted body. The above phenomenon indicated that the $\mathrm{NH}_{4}^{+} \mathrm{N}$ distribution in the wetted body was not like the transport of $\mathrm{NO}_{3}^{-}-\mathrm{N}$, i.e., transporting downward with the migration of water in the soil. In other words, the transport of $\mathrm{NH}_{4}^{+} \mathrm{N}$ did not conform to the general law of solute migration which says "salt comes with water, salt goes with water". The $\mathrm{NH}_{4}^{+} \mathrm{N}$ in soil solution is positively charged, while soil colloid is negatively charged. They will attract each other when $\mathrm{NH}_{4}^{+}-\mathrm{N}$ is in contact with soil colloid. In this way, a large amount of $\mathrm{NH}_{4}^{+}-\mathrm{N}$ in soil was adsorbed, and the $\mathrm{NH}_{4}^{+}-\mathrm{N}$ content was thus decreased rapidly, which hindered the migration of $\mathrm{NH}_{4}^{+}-\mathrm{N}$ in soil. In addition, at the same location in the wetted body, the $\mathrm{NH}_{4}^{+} \mathrm{-}$ contents increased with the increase of the initial moisture content. Under different initial moisture content, the measured $\mathrm{NH}_{4}^{+} \mathrm{N}$ content in the wetted body at the center of the film hole were 440.40, 453.40, 459.00, 461.70 and $4774.30 \mathrm{mg} / \mathrm{kg}$, respectively. If $\theta_{0}=6.02 \%$ was taken as a benchmark, then the increases of the $\mathrm{NH}_{4}^{+} \mathrm{N}$ content were $2.95 \%$, $1.27 \%, 0.61 \%$ and $2.86 \%$, respectively.

It could be seen from Figures $9 \mathrm{c}$ and $9 \mathrm{~d}$ that the $\mathrm{NH}_{4}^{+} \mathrm{N}$ content changed obviously with the proceeding of the redistribution Generally speaking, with the proceeding of the redistribution of water in the soil, the wetting front continued to move downward, 
and $\mathrm{NH}_{4}^{+}-\mathrm{N}$ in the wetted body also gradually moved downward, and its content showed a decreasing trend. In the redistribution process, a part of $\mathrm{NH}_{4}^{+}-\mathrm{N}$ in the soil migrated with water, and part of $\mathrm{NH}_{4}^{+} \mathrm{-}$ underwent a nitration reaction under the action of microorganisms in the soil. Specifically, within redistribution 24 and 48 hours, within the depth of $0-5 \mathrm{~cm}$, the $\mathrm{NH}_{4}^{+}-\mathrm{N}$ in the wetted body gradually decreased, which was especially obvious in the soil at the center of the film hole; at the end of the infiltration and within redistribution 24 and 48 hours, the $\mathrm{NH}_{4}^{+} \mathrm{-}$ content in the soil at the center of the film hole were $440.40,408.58$, and $348.90 \mathrm{mg} / \mathrm{kg}$, respectively. If the $\mathrm{NH}_{4}^{+} \mathrm{N}$ content at the end of the infiltration

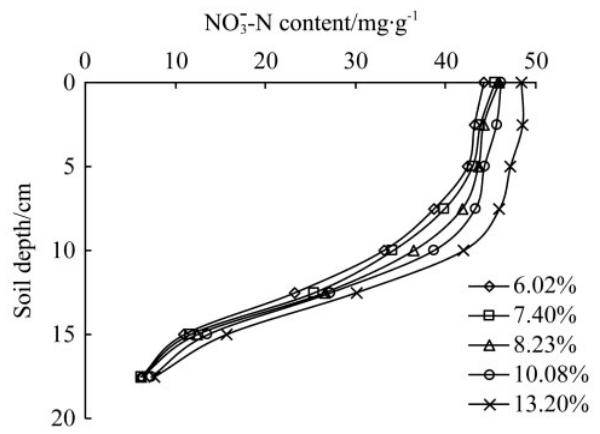

a. $\mathrm{NH}_{4}^{+}-\mathrm{N}$ content in the vertical direction at the end of the infiltration

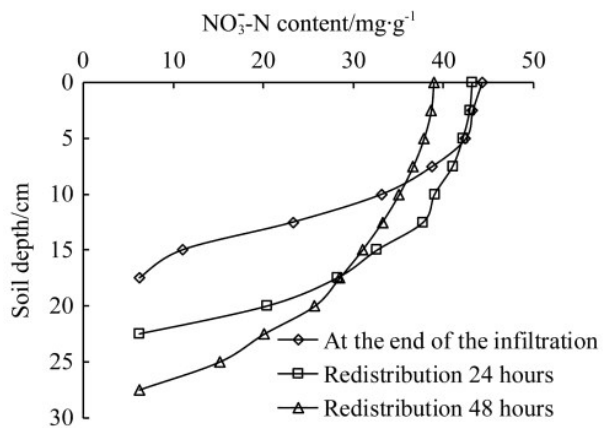

c. $\mathrm{NH}_{4}^{+}-\mathrm{N}$ content in the vertical direction after redistribution $\left(\theta_{0}=6.02 \%\right)$ was taken as a benchmark, then the decreases of the $\mathrm{NH}_{4}^{+}-\mathrm{N}$ content in the soil were $7.23 \%$ and $20.78 \%$, respectively. With the proceeding of the redistribution, the distribution of water in the wetted body was more uniform, and the closer it got to the surface of the soil, the better the soil aeration was, which also to some extent promoted the nitrification of $\mathrm{NH}_{4}^{+} \mathrm{N}$ in the soil. In addition, the $\mathrm{NH}_{4}^{+} \mathrm{-}$ content in the soil at the center of the film hole changed a lot because of the loss of $\mathrm{NH}_{4}^{+} \mathrm{N}$ through volatilization loss. Within the depth of 5-30 cm, the $\mathrm{NH}_{4}^{+}-\mathrm{N}$ content in the wetted body increased gradually.

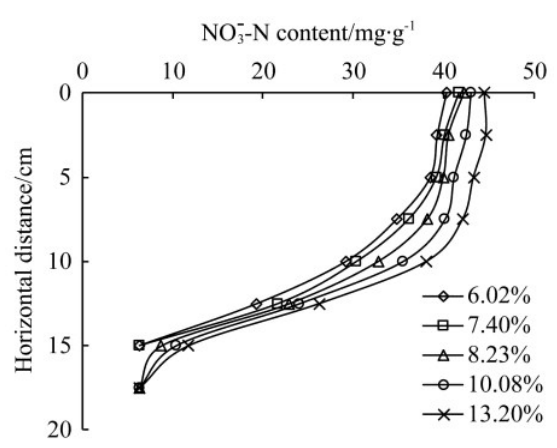

b. $\mathrm{NH}_{4}^{+} \mathrm{N}$ content in the horizontal direction at the end of the infiltration

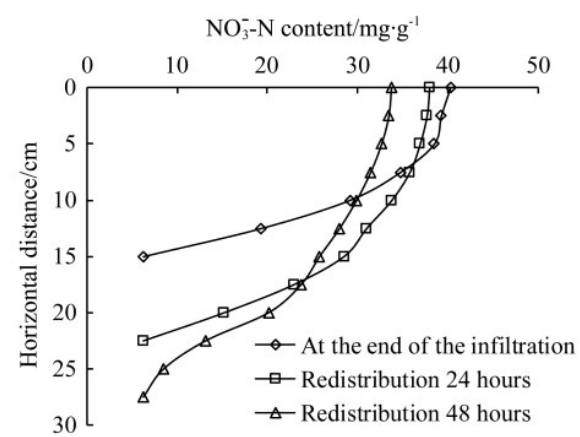

d. $\mathrm{NH}_{4}^{+}-\mathrm{N}$ content in the horizontal direction after redistribution $\left(\theta_{0}=6.02 \%\right)$

Figure 9 Soil $\mathrm{NH}_{4}^{+}-\mathrm{N}$ content in the horizontal and vertical direction of the film hole center

\section{Discussion}

The purpose of this study was to investigate the effects of initial moisture content $\left(\theta_{0}\right)$ on characteristics of soil water and nitrogen transport under muddy water film hole infiltration. Firstly, based on the laboratory infiltration experiment data, and combined with the boundary characteristics of the test device, a muddy water film fertilizer solution free infiltration model under the experimental setting conditions was developed. Initial moisture content had a significant effect on soil water and nitrogen transport under muddy water film hole irrigation. The transport of water and nitrogen in the soil was closely related to soil porosity and nitrogen content ${ }^{[8,16]}$.

In this experiment, the cumulative infiltration per unit film hole area increased with the increase of $\theta_{0}$. The functional models of vertical and horizontal distances of wetting front migration were fitted, and the effect of $\theta_{0}$ on the fitting parameters was revealed. In the process of film hole infiltration, the film hole acted as the only "channel" through which the water entered the soil. In this way, water infiltrated into the soil under the influence of the film hole chamber water head, and the soil at the center of the film hole was in contact directly with water. Therefore, the soil near the film hole had the largest water content, which was basically close to saturated water content. Isolines of moisture content distribution were relatively sparse, and the change gradient of water content was relatively small. In addition, in the infiltration of 720 min, $\mathrm{NO}_{3}^{-}-\mathrm{N}$ was mainly distributed within a distance of $15 \mathrm{~cm}$ away from the film hole center. This phenomenon further showed the advantage of film hole infiltration, i.e., the fertilizer could be retained in the shallow soil where the root zone of crops was located. This not only was conducive to the absorption and utilization of nutrients by crops but also could improve the utilization of nitrogen fertilizer ${ }^{[18,23]}$. In the process of film hole infiltration, water and nutrients hardly leak to deep soil, and film hole infiltration is, therefore, water-saving and can reduce the pollution of $\mathrm{NO}_{3}^{-}-\mathrm{N}$ to groundwater ${ }^{[11,24]}$. However, as this study has only completed the laboratory test, further study is needed for the field application and the parameter optimization of the model.

The Kostiakov model is a relatively classical and traditional theoretical model and is usually used to characterize the process of soil water infiltration ${ }^{[25,26]}$. The present study applied the Kostiakov model to the simulation of the cumulative infiltration of muddy water film hole infiltration, and the fitting effect of the model was significant, and the coefficient of determination was greater than 0.99 . The conclusions of this study were consistent with the findings of Zhong et al. ${ }^{[27]}$ who have found that the maximum of $\mathrm{NO}_{3}^{-}-\mathrm{N}$ content appeared near the film hole center ${ }^{[18]}$. At the same location, the higher $\theta_{0}$, the higher average soil 
moisture content, which was similar to the results of this study. Moreover, this study is still different from the actual situation and has some limitations. In the actual film hole irrigation, muddy water flows freely along with the film and has the characteristics of flow $^{[15,16]}$. The emphasis of this paper was on the change of cumulative infiltration and steady infiltration rate with time, that is, the study of the infiltration process. The findings presented in this study might only be suitable and reasonable for the study area investigated, and the model was mainly put forward for specific test conditions, which wasn't universal, but the research method would provide a reference for studies on the infiltration characteristics of film hole irrigation in other regions.

\section{Conclusions}

In this study, laboratory experiments were conducted with muddy water film hole irrigation, using five initial soil moisture content treatments. The models about 1) the relationship between the cumulative infiltration per unit film hole area $(I(t))$ and infiltration duration $(t) ; 2)$ the relationship among the horizontal and vertical migration distances of the wetting front $\left(F_{x}, F_{z}\right), \theta_{0}$ and $t$, were established. Kostiakov infiltration model could fit the relationship between $I(t)$ and $t$. With the increase of $\theta_{0}$, the infiltration coefficient $(K)$ gradually decreased, but the infiltration index $\alpha$ remains basically unchanged. $\mathrm{NO}_{3}^{-}-\mathrm{N}$ was mainly distributed within the range of the wetting radius of $15 \mathrm{~cm}$, while $\mathrm{NH}_{4}^{+}-\mathrm{N}$ was mainly distributed within the range of the wetting radius of $8 \mathrm{~cm}$. This study could provide a theoretical basis and technical support for further study on soil water and nitrogen transport under muddy water film hole irrigation.

\section{Acknowledgements}

This study was financially supported by the National Key Research and Development Program of China (Grant No. 2016YFC0400204), the National Natural Science Foundation of China (Grant No. 52079105, 51779205 and 51479161), and the Public welfare industry research special project (Grant No. 201203003). The authors acknowledge the anonymous reviewers and the editor for their valuable comments and suggestions.

\section{[References]}

[1] Karthe D, Chalov S, Borchardt D. Water resources and their management in central Asia in the early 21 century: status, challenges and future prospects. Environmental Earth Sciences, 2014; 73(2): 487-499.

[2] Swatuk L, Mcmorris M, Leung C, Zu Y. Seeing "invisible water": challenging conceptions of water for agriculture, food and human security. Canadian Journal of Development Studies/Revue Canadienne D'études Du Développement, 2015; 36(1): 24-37.

[3] Deng X P, Shan L, Zhang H, Turner N C. Improving agricultural water use efficiency in arid and semiarid areas of China. Agricultural Water Management, 2016; 80(1-3): 23-40.

[4] Yang J, Mao X M, Wang K, Yang W C. The coupled impact of plastic film mulching and deficit irrigation on soil water/heat transfer and water use efficiency of spring wheat in northwest China. Agricultural Water Management, 2018; 201: 232-245.

[5] Li S E, Kang S Z, Zhang L, Ortega-Farias S, Li F S, Du T S, et al. Measuring and modeling maize evapotranspiration under plastic film-mulching condition. Journal of Hydrology, 2013; 503: 153-168.

[6] Ali S, Xu Y Y, Jia Q M, Ma X C, Ahmad I, Adnan M, et al. Interactive effects of plastic film mulching with supplemental irrigation on winter wheat photosynthesis, chlorophyll fluorescence and yield under simulated precipitation conditions. Agricultural Water Management, 2018; 207: 1-14.
[7] Li R, Hou X Q, Jia Z K, Han Q F, Ren X L, Yang B P. Effects on soi temperature, moisture, and maize yield of cultivation with ridge and furrow mulching in the rainfed area of the Loess Plateau, China. Agricultural Water Management, 2013; 116: 101-109.

[8] Selim T, Bouksila F, Berndtsson R, Persson M. Soil water and salinity distribution under different treatments of drip irrigation. Soil Science Society of America Journal, 2013; 77(4): 1144-1156.

[9] Fan Y W, Gong J G, Wang Y, Shao X X, Zhao T. Application of Philip infiltration model to film hole irrigation. Water Supply, 2019; 19(3): 978-985.

[10] Steinmetz Z, Wollmann C, Schaefer M, Buchmann C, David J, Tröger J, et al. Plastic mulching in agriculture. Trading short-term agronomic benefits for long-term soil degradation? Science of the Total Environment, 2016; 550: 690-705.

[11] Li Y B, Fan Y W, Liu Y, Ma X Y. Influencing factors and simplified model of film hole irrigation. Water, 2017; 9(7): 1-18

[12] Gupta A D, Babel M S, Ashrafi S. Effect of soil texture on the emission characteristics of porous clay pipe for subsurface irrigation. Irrigation Science, 2009; 27(3): 201-208.

[13] Liu X H, He B L, Yi X, Zhang L G, Han F F. The soil water dynamics and hydraulic processes of crops with plastic film mulching in terraced dryland fields on the Loess Plateau. Environmental Earth Sciences, 2016; 75(9): 1-16.

[14] Saeed M, Mahmood S. Application of film hole irrigation on borders for water saving and sunflower production. Arabian Journal for Science and Engineering, 2013; 38(6): 1347-1358.

[15] Fei L J, Wang J H, Jin S J. Free infiltration characteristics of muddy water film hole irrigation with different film hole diameters. Transactions of the CSAM, 2016; 47(2): 172-178. (in Chinese)

[16] Liu L H, Fei L J, Chen L, Hao K. Effects of sediment concentration of muddy water on water and nitrogen transport characteristics under film hole irrigation with fertilizer infiltration. Transactions of the CSAE, 2020 36(2): 120-129. (in Chinese)

[17] Jie F L, Fei L J, Zhong Y, Liu L H, Kang S X. Wetting body characteristics and infiltration model of film hole irrigation. Water, 2020; 12(5): $1-14$

[18] Dong Y Y, Mu H W, Fei L J. Experimental study on influence factor under single film hole fertilizer solution infiltration. China Rural Water and Hydropower, 2015; 10: 5-9. (in Chinese)

[19] Jin S J, Fei L J, Fu Y L, Wang J H, Zhong Y, Chen L. Effect of initial soil moisture content on single-line interference infiltration characteristics of muddy water film hole irrigation. Journal of Soil and Water Conservation, 2016; 5: 235-239, 254. (in Chinese)

[20] Zhong Y, Fei L J, Fu Y L, Jin S J, Wang J H. Influence of soil bulk density on single hole point source free infiltration characteristics of muddy water film hole irrigation. Journal of Soil and Water Conservation, 2016; 2: 88-91, 96. (in Chinese)

[21] Yao X, Li J S, Huang X Q, Sun X L. Distribution of Yellow River's silt in field under border irrigation. Transactions of the CSAE, 2016; 32(18): 147-152. (in Chinese)

[22] Kostiakov A N. On the dynamics of the coefficient of water-percolation in soils and on the necessity of studying it from a dynamic point of view for purposes of amelioration. Transactions of 6th Commission of the International Society of Soil Science, Russia, 1932; Part A: 17-21.

[23] Almeida W S D, Panachuki E, Oliveira P T S D, Menezes R D S, Sobrinho T A, Carvalho D F D. Effect of soil tillage and vegetal cover on soil water infiltration. Soil and Tillage Research, 2018; 175: 130-138.

[24] Fan Y W, Shao X X, Gong J G, Wang Y. An empirical model for estimating soil wetting pattern dimensions during film hole irrigation. Archives of Agronomy and Soil Science, 2020; 66(13): 1765-1779.

[25] Fu Q, Hou R J, Li T X, Li Y, Liu D, Li M. A new infiltration model for simulating soil water movement in canal irrigation under laboratory conditions. Agricultural Water Management, 2019; 213: 433-444.

[26] Liu L H, Fei L J, Zhu H Y, Hao K, Jie F L. Study on the influence of fertilizer solution concentration on soil water and nitrogen transport characteristics under film hole irrigation. Journal of Soil Science and Plant Nutrition, 2021; 21: 1653-1665.

[27] Zhong Y, Fei L J, Li Y B. Infiltration characteristics of film hole irrigation under the influence of multiple factor. Irrigation and Drainage, 2020; 69(3): 417-426. 